\title{
Article
}

\section{NMR Study of Solvation Effect on Geometry of Proton-Bound Homodimers of Increasing Size}

Andrei A. Gurinov, Gleb S. Denisov, Alexandra O. Borissova, Alexander S.

Goloveshkin, Julian Greindl, Hans-Heinrich Limbach, and Ilya G. Shenderovich

J. Phys. Chem. A, Just Accepted Manuscript • DOI: 10.1021/acs.jpca.7b09285 • Publication Date (Web): 24 Oct 2017

Downloaded from http://pubs.acs.org on October 29, 2017

\section{Just Accepted}

"Just Accepted" manuscripts have been peer-reviewed and accepted for publication. They are posted online prior to technical editing, formatting for publication and author proofing. The American Chemical Society provides "Just Accepted" as a free service to the research community to expedite the dissemination of scientific material as soon as possible after acceptance. "Just Accepted" manuscripts appear in full in PDF format accompanied by an HTML abstract. "Just Accepted" manuscripts have been fully peer reviewed, but should not be considered the official version of record. They are accessible to all readers and citable by the Digital Object Identifier (DOI®). "Just Accepted" is an optional service offered to authors. Therefore, the "Just Accepted" Web site may not include all articles that will be published in the journal. After a manuscript is technically edited and formatted, it will be removed from the "Just Accepted" Web site and published as an ASAP article. Note that technical editing may introduce minor changes to the manuscript text and/or graphics which could affect content, and all legal disclaimers and ethical guidelines that apply to the journal pertain. ACS cannot be held responsible for errors or consequences arising from the use of information contained in these "Just Accepted" manuscripts. 


\section{INTRODUCTION}

Hydrogen bonding (H-bonding) is often the main noncovalent interaction in a molecular system under study which defines both its physical properties and its chemical fate. The latter generally involves proton transfer as one of the reaction steps. ${ }^{1}$ The simplest case is intramolecular proton transfer in small molecules in the solid state. $^{2-5}$ The presence of competing H-bonds and solvent complicates the analysis. ${ }^{6-8}$ Sophisticated theoretical tools are required in order to simulate enzymatic reactions and transporters and receptors activity at the atomic level..$^{-11}$ At the current stage of knowledge, it is possible to predict the effect of a mutation on the fate of a particular biosystem, to prove this prediction experimentally, and to explain it theoretically. ${ }^{12}$ However, for many formally simple systems experimental results have not been reproduced in silico at a reasonable approximation; the strength of dispersive interactions in solution, ${ }^{13}$ spectroscopic signatures of protonated water clusters ${ }^{14,15}$ and hydrated hydroxyl anion, ${ }^{16}$ the structure of water-base complexes in aprotic solutions ${ }^{17}$ and amorphous solids ${ }^{18-}$ 20 are among such problems. In such cases, the measured spectral parameters have to be assigned to a certain geometry or energy using empirical correlations. ${ }^{21-25}$

In the past, some of us reported on geometry of the proton-bound homodimers of ortho-unsubstituted and ortho-substituted pyridine derivatives in an aprotic polar solution. ${ }^{26}$ For the ortho-unsubstituted homodimers we observed experimentally a monotonous dependence of the N...N distance on the gas-phase proton affinity (PA) of the involved pyridines. For such homodimers, this dependence can be correlated with a qualitatively similar dependence of the binding energy as established by quantum mechanical calculations of isolated species. ${ }^{27}$ The effect of the solvent reaction field on the geometries of formally symmetric NHN H-bonds remains a debatable question. Sophisticated calculations predict an increase of the N...N distance in a polar solvent. ${ }^{28,29}$ The available experimental data contradict this conclusion. $3^{30} \mathrm{~A}$ discrepancy between experimental and theoretical results was demonstrated recently in an extensive study of bond dissociation equilibria of a variety of proton-bound homodimers. ${ }^{13}$ In any case, the N...N distance in protonbound homodimers depends on both the protonaccepting power of the base and the features of solvation. The latter effect should be sensitive to the homodimer's size.

The objective of the present work is to study experimentally the effect of solvation on the geometry of proton-bound homodimers and its dependence on the size of the complexes. For this purpose, we have measured the ${ }^{1} \mathrm{H}$ NMR chemical shifts of mobile protons in conjugate acids (that are protonated bases in our case) and proton-bound homodimers for two series of quinoline and acridine derivatives in a polar aprotic solvent in the slow intermolecular exchange regime. The values of these chemical shifts 
have been used to estimate the $\mathrm{H}$-bond geometries of the homodimers. The symmetries of these homodimers have been explored by measuring the sign of the primary isotope effects on the NMR chemical shift: ${ }^{p} \Delta(H / D) \equiv \delta(N \underline{D} N)-\delta(N \underline{H} N)$.

The species studied are listed in Figure 1.

Figure 1. Quinoline (a-g) and acridine (h,i) derivatives and anions $(\mathbf{j}, \mathbf{k})$ used in this work. 6-chloroquinoline (a), quinoline (b), 3-methylquinoline (c), 7-methylquinoline (d), 4chloro-2-methylquinoline (e), 2-methylquinoline (f), 2,6dimethylquinoline (g), 9-chloroacridine (h), acridine (i), tetrafluoroborate $\left(\left[\mathrm{BF}_{4}\right]^{-}\right) \quad(\mathbf{j})$, and tetrakis $\left[3,5^{-}\right.$ bis(trifluoromethyl)phenyl]-borate $\left([\mathrm{BArF}]^{-}\right)(\mathbf{k})$.
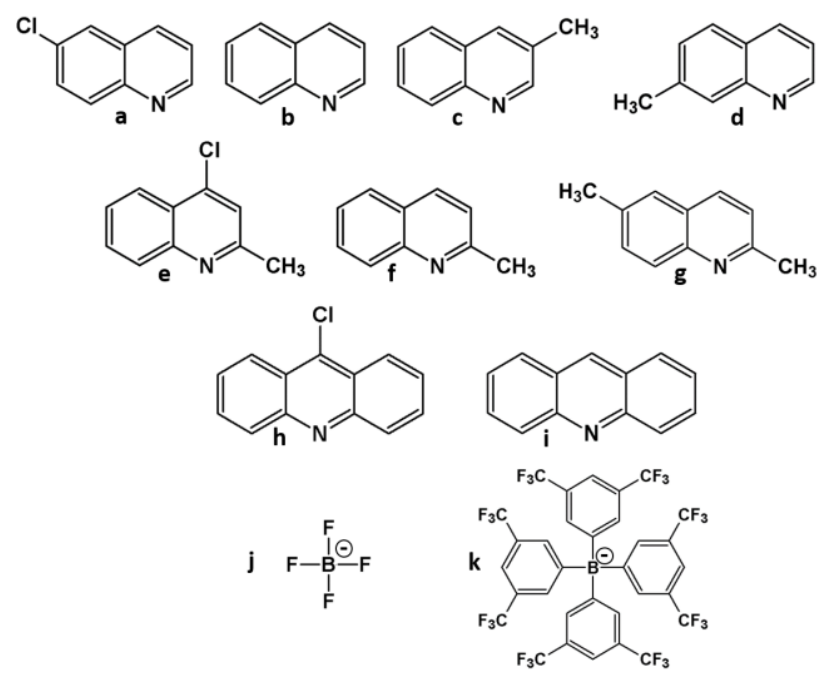

\section{EXPERIMENTAL SECTION}

\section{Materials.}

Chemicals were purchased from Sigma-Aldrich and used after additional purification by sublimation or distillation. The deuterated freon gas mixture $\mathrm{CDF}_{3} / \mathrm{CDClF}_{2}$ for the low-temperature NMR experiments, whose composition varied between 1:2 and 1:3, was prepared from chloroform- $\mathrm{d}_{1} \cdot 3^{1}$

Sodium tetrakis[3,5-bis(trifluoromethyl)phenyl]-borate $(\mathrm{Na}[\mathrm{BArF}])$ was prepared as described recently.32,33

\section{Complexes.}

The general procedure of preparing complexes of bases with $\mathrm{H}\left[\mathrm{BF}_{4}\right]$ was as follows. Equimolar quantities of the base and of $\mathrm{H}\left[\mathrm{BF}_{4}\right](50 \%$ aqueous solution) were mixed in dichloromethane and stirred for $3 \mathrm{~h}$ at $30{ }^{\circ} \mathrm{C}$. Dichloromethane and water were then removed by repeated azeotropic distillation leaving a solid product. Complexes of bases with $\mathrm{H}[\mathrm{BArF}]$ were obtained as follows. Equimolar amounts of the base and $\mathrm{Na}[\mathrm{BArF}]$ were mixed in $10 \mathrm{ml}$ of water with a drop of $37 \% \mathrm{HCl}$ and stirred for $12 \mathrm{~h}$ at $50^{\circ} \mathrm{C}$. The precipitated salts were filtrated, washed with water and dried under vacuum. The procedure of obtaining proton-bound homodimers was as follows. Equimolar amounts of the base and of the complex of the base with $\mathrm{H}\left[\mathrm{BF}_{4}\right]$ or $\mathrm{H}[\mathrm{BArF}]$ were mixed directly in an NMR tube. Deuteration of complexes was performed by repeatedly dissolving them in methanol-OD (Eurisotop) and removing the solvent under vacuum.
Crystals of $[\text { Acridine- } \mathrm{H}]^{+} \ldots$ Acridine $[\mathrm{BArF}]^{-}$were prepared as follows: acridine ( $352 \mathrm{mg}), 37 \% \mathrm{HCl}(8 \mathrm{o} \mu \mathrm{L})$, and $\mathrm{Na}[\mathrm{BArF}]$ (870 mg) were dissolved in water and stirred overnight. The precipitate was filtrated and dried under vacuum. The powder was crystallized in solution of either toluene or chloroform.

\section{NMR Measurements.}

Liquid-state ${ }^{1} \mathrm{H}$ and ${ }^{2} \mathrm{H}$ NMR spectra were measured on a Bruker AMX 500 spectrometer operated at 11.7 Tesla equipped with a probe-head enabled to perform experiments down to $100 \mathrm{~K}$. The spectra were indirectly referenced to tetramethylsilane (TMS) by setting the central component of the residual $\mathrm{CHClF}_{2}$ triplet of the freon mixture to $7.18 \mathrm{ppm}$. The standard ${ }^{1} \mathrm{H}$ NMR spectra were recorded with recycle times of $3 \mathrm{~s}$.

\section{XRD Measurements.}

X-ray diffraction data for single crystals were collected using a "Bruker APEX-II" CCD diffractometer. The samples were kept at $100 \mathrm{~K}$ during data collection. Olex2 software package was used for the data analysis. The structure was solved with the XS structure solution program using the Direct Methods and refined with the XL refinement package using the least squares minimisation. All nonhydrogen atoms were refined with anisotropic thermal parameters. The disordered solvent molecules of toluene were split to two parts and refined with restrains on bonds, angles (FRAG command) and thermal displacement ellipsoids (SIMU command). The atomic coordinates, the bond lengths, the angles, and the thermal parameters have been deposited at the Cambridge Crystallographic Data Centre (CCDC) with numbers 1552802 and 1552803 .

\section{COMPUTATIONAL DETAILS}

The locations of the binding protons in the crystalline phases were estimated using DFT calculations in the following way. The coordinates of all atoms of the [AcridineH...Acridine $]^{+}$moiety were taken from the XRD experiment and kept frozen, except the positions of the mobile protons. Their locations were optimized at the $B_{3} L Y P$ approximation using the $6-311++\mathrm{G}(3 \mathrm{df}, 2 \mathrm{p})$ basis set of the Gaussian 16.A.03 package. ${ }^{36}$

The gas-phase proton affinities (PA) of selected pyridine derivatives and of compounds a-i in the gas phase were calculated as follows: $P A=\Delta H^{298}(B)+5 R T / 2-\Delta H^{298}\left(B H^{+}\right)$.

Here, $\Delta H^{298}(B)$ and $\Delta H^{298}\left(B H^{+}\right)$stand for the sums of electronic and thermal enthalpies of a base and its conjugate acid at $298 \mathrm{~K}$. The enthalpies were estimated at the B3LYP/6-311++g(3df,2p) level. This level provides a reasonable description of the structure and harmonic frequencies of the neutral and charged $\mathrm{H}$-bonded systems in the gas phase. 37 It is also sufficient to obtain correct values of enthalpies. $3^{8}$ Effective proton affinities $\left(\mathrm{PA}^{\varepsilon}\right)$ in solutions were calculated at the same level using the Polarizable Continuum Model (PCM) approximation39 at $\varepsilon=$ 108.94 (formamide in the list of Gaussian's solvents) as follows:

$P A^{\varepsilon}=\Delta H^{298, \varepsilon}(B)+\Delta H^{298, \varepsilon}\left(H^{+}\right)-\Delta H^{298, \varepsilon}\left(B H^{+}\right)$. 
Here, $\Delta H^{298, \varepsilon}(B), \Delta H^{298, \varepsilon}\left(B H^{+}\right)$, and $\Delta H^{298, \varepsilon}\left(H^{+}\right)$stand for the sums of electronic and thermal enthalpies of a base, its conjugate acid, and proton at $298 \mathrm{~K}$ and the relative permittivity $\varepsilon>1$.

\section{RESULTS}

In Figure 2 are shown low-temperature NMR spectra of the conjugate acids and the proton-bound homodimers of a-i with $\left[\mathrm{BF}_{4}\right]^{-}$as counteranion and $\mathrm{CDF}_{3} / \mathrm{CDF}_{2} \mathrm{Cl}$ as solvent. Because of salt precipitation at low temperatures, we succeeded to measure spectra using [BArF] as counteranion only for the homodimers of $\mathbf{e}$ and $\mathbf{g}$. In all cases the slow intermolecular proton and $\mathrm{H}$-bond exchange regime was achieved. For the deuteron-bound homodimers of b-d, f, and g we obtained ${ }^{2} \mathrm{H}$ NMR spectra using $\left[\mathrm{BF}_{4}\right]^{-}$as counteranion from which we could obtain ${ }^{p} \Delta(H / D)$. All measured NMR data are collected in Table 1.

Figure 3 depicts the general view of the proton-bound homodimer of $\mathbf{i}$ with $[\mathrm{BArF}]^{-}$according to X-ray diffraction analysis. The structural parameters depend on the solvent used for crystallization because the unit cell includes one solvent molecule in addition to the homodimer and the anion. The N...N distances and the angles between the aromatic planes are $2.754 \AA$ and $2.743 \AA, 62^{\circ}$ and $84^{\circ}$ in cocrystals with chloroform and toluene, respectively.

Figure 2. Left-hand: the mobile-proton part of the ${ }^{1} \mathrm{H}$ NMR spectra of the conjugate acids of a-i. Right-hand: the mobileproton part of the ${ }^{1} \mathrm{H}$ and ${ }^{2} \mathrm{H}$ (inserts) NMR spectra of the proton-bound homodimer of a-i. Solvent: $\mathrm{CDF}_{3} / \mathrm{CDF}_{2} \mathrm{Cl}$. Temperature: $120 \mathrm{~K}$. Anion: $\left[\mathrm{BF}_{4}\right]^{-}$.
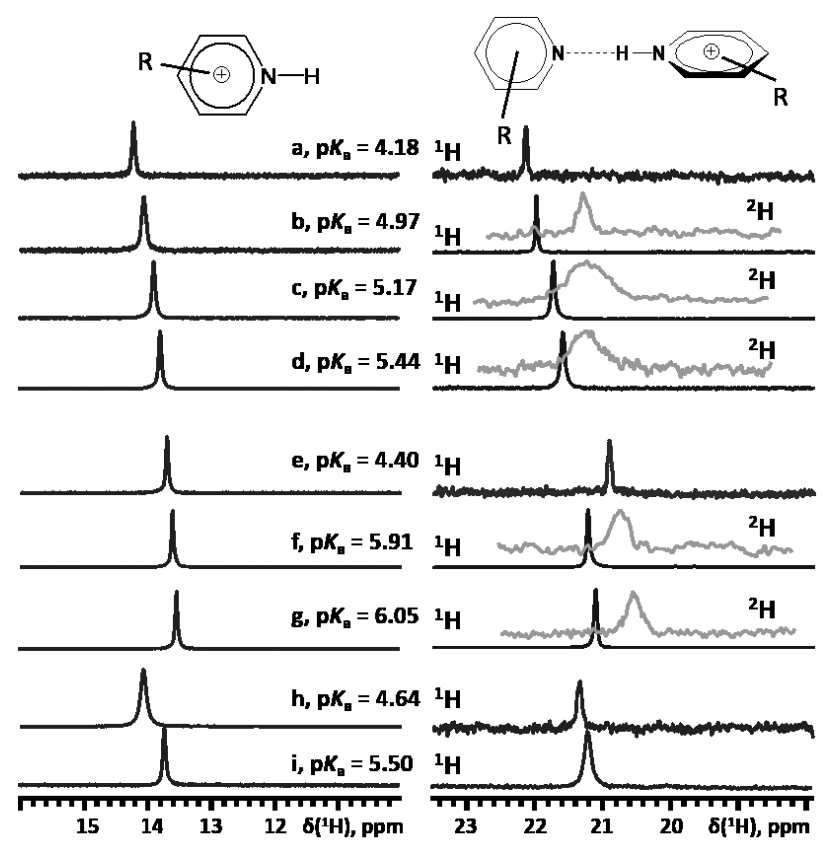

\section{DISCUSSION}

X-ray diffraction analysis demonstrates that the structure of the proton-bound homodimer of acridine resembles the one of pyridine. $4^{\circ}$ In the latter case the $\mathrm{N}$...N distance was shorter (2.655 $\AA$ ) and the unit cell did not contain the crystallization solvent. The estimated dis- tances in [Acridine-H...Acridine] ${ }^{+}$are $\mathrm{N}-\mathrm{H}=1.075 \AA$ and $1.078 \AA$, H...N = $1.679 \AA$ and $1.665 \AA$ for the cocrystals with chloroform and toluene, respectively. The $\mathrm{H}$-bonds are linear in both cases. For comparison, in the proton-bound homodimer of pyridine these distances are $1.123 \AA$ and $1.532 \AA$, while the NHN angle is $171^{\circ} .4^{\circ}$

Table 1. Experimental NMR parameters of conjugate acids and homodimers at $120 \mathrm{~K}$.

\begin{tabular}{|c|c|c|c|c|}
\hline \multirow[t]{3}{*}{ base } & conjugate acid & \multicolumn{3}{|c|}{ homodimer } \\
\hline & \multirow{2}{*}{$\begin{array}{c}\delta\left({ }^{1} \mathrm{H}\right) \\
\pm 0.01 \mathrm{ppm} \\
{\left[\mathrm{BF}_{4}\right]^{-}}\end{array}$} & \multicolumn{2}{|c|}{$\begin{array}{c}\delta\left({ }^{1} \mathrm{H}\right) \\
\pm 0.01 \mathrm{ppm}\end{array}$} & \multirow{2}{*}{$\begin{array}{c}\Delta(\mathrm{H} / \mathrm{D})^{\mathrm{a}} \\
\pm 0.05 \mathrm{ppm} \\
{\left[\mathrm{BF}_{4}\right]^{-}}\end{array}$} \\
\hline & & {$[\mathrm{BArF}]^{-}$} & {$\left[\mathrm{BF}_{4}\right]^{-}$} & \\
\hline $\mathrm{a}$ & 14.21 & - & 22.12 & - \\
\hline b & 14.07 & - & 22.00 & -0.95 \\
\hline C & $13 \cdot 90$ & - & 21.74 & -0.70 \\
\hline d & 13.80 & - & 21.60 & -0.50 \\
\hline e & $13 \cdot 71$ & 20.89 & 20.93 & - \\
\hline$f$ & 13.63 & - & 21.23 & -0.63 \\
\hline g & 13.53 & 21.06 & 21.12 & -0.78 \\
\hline h & 14.05 & - & 21.35 & - \\
\hline $\mathrm{i}$ & $13 \cdot 72$ & - & 21.31 & - \\
\hline
\end{tabular}

aprimary isotope effects on the NMR chemical shifts ${ }^{p} \Delta(H / D) \equiv \delta(N \underline{D} N)-\delta(N \underline{H} N)$

Figure 3. The general view of the proton-bound homodimer of $\mathbf{i}$ with $[\mathrm{BArF}]^{-}$according to X-ray diffraction analysis. The unit cell includes, besides the homodimer and the anion, one molecule of the solvent.

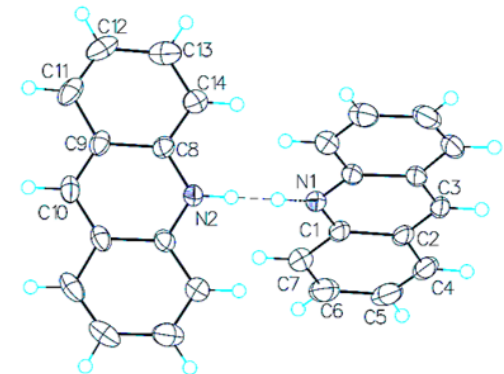

The sign of the primary isotope effect on the NMR chemical shift is considered to be of diagnostic value for the H-bond symmetry, as has been found in a number of experimental and theoretical studies.41-46 Namely, in most cases, the binding proton is located closer to one side of the $\mathrm{H}$-bond and ${ }^{p} \Delta(H / D)<$ o. There are a few exceptions when the proton is bound equally strong to both partners. In these cases it is located near the center of the H-bond and ${ }^{p} \Delta(H / D)>0$. However, some of us showed that ${ }^{p} \Delta(H / D)$ can be positive for an asymmetric $\mathrm{H}$-bond as well.47 The reason is that the shape of the shielding function of the internal vibrational coordinates can be rather exclusive for each complex. The primary factor that determines the symmetry of the $\mathrm{H}$-bond in a protonbound homodimer is the electronegativity of the partners. 48,49 The bond is expected to be symmetric for fluorine, oxygen, and sp-hybridized nitrogen bases, while 
asymmetric for $\mathrm{sp}^{2}$ - and $\mathrm{sp}^{3}$-hybridized nitrogen bases. $4^{8}$ The asymmetry can be also induced by steric hindrance. $\mathrm{H}$-bonds in the proton-bound homodimer of pyridine derivatives are asymmetric; the reversible proton transfer between the two pyridines is fast in the millisecond timescale down to $120 \mathrm{~K}$ and slower than $10^{11} \mathrm{~s}^{-1}$ up to 290K.40,50 The latter estimate was obtained by means of vibrational spectroscopy. This finding is in agreement with the theoretical estimations of the barrier for the proton transfer of $4 \mathrm{~kJ} / \mathrm{mol} .^{5^{1}}$ The rate-limiting step for the proton transfer in this double-well potential is the solvent reorganization.52-54 This effect is important in enzyme catalysis. 55 In the proton-bound homodimer of quinoline derivatives b-d, f, and $\mathbf{g}{ }^{p} \Delta(H / D)$ is negative as expected.

Experimental estimation of $\mathrm{H}$-bond geometry. The most justified NMR parameter for the quantitative analysis of $\mathrm{H}$-bond geometries in the case of nitrogencontaining aromatic rings is the ${ }^{15} \mathrm{~N}$ NMR chemical shift. ${ }^{6}$ In the past, some of us used this chemical shift to correlate $\mathrm{H}$-bond geometries with other NMR parameters, namely, $J_{15_{N}{ }^{1} H}$ coupling constants and ${ }^{1} \mathrm{H}$ NMR chemical shifts. The latter parameter is used here to estimate the $\mathrm{H}$-bond geometry of the proton-bound homodimers.

For a detailed discussion about geometric and NMR parameter correlations for $\mathrm{H}$-bonds we refer to other publications.57-59 As described in Ref. 26, the ${ }^{1} \mathrm{H}$ NMR chemical shift of the binding proton correlates with the valence bond orders $p_{i=1,2}^{*}$ of the N-H and N...H bonds as follows: $\delta\left({ }^{1} H\right)=\delta^{0}\left({ }^{1} H\right) \cdot\left(p_{1}^{*}+p_{2}^{*}\right)+\Delta_{H} \cdot 4 \cdot p_{1}^{*} \cdot p_{2}^{*} \quad($ eq $\quad 1)$. The parameter $\delta^{0}\left({ }^{1} H\right)$ stands for the limiting chemical shift in a fictive free conjugate acid. $\Delta_{H}$ is an empirical fitting parameter the value of which lies in the range of 10 to 20 ppm.57,58,60 For the proton-bound homodimer of pyridine it was estimated to be $15.8 \mathrm{ppm} ;{ }^{26}$ this value was used in this work for all species. The parameters $p_{1}^{*}$ and $p_{2}^{*}$ are dependent and can be expressed as follows: $p_{1}^{*}=p-(p \cdot(1-p))^{2} \cdot\left(250 \cdot(p \cdot(1-p))^{3} \cdot(2 p-1)+0.85\right)$ and $p_{2}^{*}=1-p-(p \cdot(1-p))^{2} \cdot\left(250 \cdot(p \cdot(1-p))^{3} \cdot(1-2 p)+0.85\right)$, where $0<p<1$. These parameters were derived numerically for a given $\delta\left({ }^{1} H\right)$ from eq 1. $p_{1}^{*}$ and $p_{2}^{*}$ define two distances $r_{1}$ and $r_{2}$ as follows: $r_{1}=-\ln \left(p_{1}^{*}\right) \cdot 0.37 \AA+0.997 \AA$ and $r_{2}=-\ln \left(p_{2}^{*}\right) \cdot 0.37 \AA+0.997 \AA$. Here, we lable the shortest one of them as $r_{N H}$ and their sum as $r_{N N}$. We refer to Ref. 26 for a detailed explanation.

The margin of error for the estimates of $r_{N H}$ and $r_{N N}$ clearly depends on the margin of error for $\delta\left({ }^{1} H\right)$. The latter is $0.01 \mathrm{ppm}$ that provides for the former margin of error a value of $0.0005 \AA .^{26}$ The systematic error cannot be evaluated at the current stage.

The only complex-specific parameter in our estimations of the N-H and N...N distances is $\delta^{0}\left({ }^{1} H\right)$. The best possible estimate of this parameter is the experimental value of $\delta\left({ }^{1} H\right)$ in the conjugate acid of the corresponding base with the non-coordinating anion [BArF]- Indeed, in the conjugate acids of pyridine derivatives with $[\mathrm{BArF}]^{-}$the values of ${ }^{1} J_{1 N_{N}{ }^{1} \mathrm{H}}$ were close to the ones in the conjugate acids of ortho-tert-butylsubstituted pyridines. ${ }^{40,61}\left[\mathrm{BF}_{4}\right]^{-}$ interacts with conjugate acids much stronger than $[\mathrm{BArF}]^{-} .33$ For pyridine derivatives in complexes [pyridine- $\mathrm{H}]^{+}[\mathrm{X}]^{-}$, where $[\mathrm{X}]^{-}=\left[\mathrm{BF}_{4}\right]^{-}$and $[\mathrm{BArF}]^{-}$, the difference of the ${ }^{1} \mathrm{H}$ NMR chemical shifts was about $3 \mathrm{ppm} .4^{\circ}$

In contrast, for the proton-bound homodimers of the pyridine derivatives the difference of the ${ }^{1} \mathrm{H}$ NMR chemical shifts in the complexes with $[\mathrm{BArF}]^{-}$and $\left[\mathrm{BF}_{4}\right]^{-}$was less than o.1 ppm. Thus, although the interaction of $\left[\mathrm{BF}_{4}\right]^{-}$ with the homodimers of ortho-unsubstituted pyridines favoured intermolecular exchange down to $120 \mathrm{~K}, 40$ this interaction did not affect the geometry of their $\mathrm{H}$-bonds. The proton-bound homodimers of $\mathbf{e}$ and $\mathbf{g}$ demonstrate that this conclusion is also valid for quinoline derivatives. The value of $\delta\left({ }^{1} H\right)$ in the conjugate acids of a-i with [BArF] $]^{-}$in $\mathrm{CDF}_{3} / \mathrm{CDF}_{2} \mathrm{Cl}$ cannot be obtained because of the low solubility. We also could not use another solvent or increase the temperature because $\delta\left({ }^{1} H\right)$ in conjugate acids depends on the solvent polarity. Indeed, for the conjugate acid of pyridine this value is $11.86 \mathrm{ppm}^{13}$ in $\mathrm{CD}_{2} \mathrm{Cl}_{2}(\varepsilon \approx 10)^{62}$ and $14.2 \mathrm{ppm}^{26}$ in $\mathrm{CDF}_{3} / \mathrm{CDClF}_{2}(\varepsilon \approx$ $30)^{31}$. In the latter case the temperature dependence of $\delta\left({ }^{1} H\right)$ was specifically noted. ${ }^{26}$ Thus, $\delta^{0}\left({ }^{1} H\right)$ for a-i has to be estimated. It is reasonable to assume that for chemically similar compounds this value correlates with their $\mathrm{p} K_{\mathrm{a}}$ and PA. Strictly speaking, the $\mathrm{p} K_{\mathrm{a}}$ 's of ionizable groups in non-aqueous environment can be estimated theoretically. ${ }^{6}$ However, such calculations are quite demanding. In contrast, the gas-phase PA's can be easily obtained and do not depend on solvation. The calculated PA's of selected pyridine derivatives and $\mathbf{a}-\mathbf{i}$ are collected in Tables 2 and 4 .

Table 2. The gas-phase proton affinity (PA) of some pyridine derivatives and ${ }^{~} \mathrm{H}$ NMR chemical shifts of the mobile protons of their conjugate acids.

\begin{tabular}{lccc} 
Base $^{\mathrm{a}}$ & $\mathrm{PA}^{\mathrm{b}}$ & \multicolumn{2}{c}{$\delta\left({ }^{1} \mathrm{H}\right), \mathrm{ppm}^{\mathrm{c}}$} \\
\cline { 3 - 4 } & $\mathrm{kJ} / \mathrm{mol}$ & {$\left[\mathrm{BF}_{4}\right]^{-}$} & {$[\mathrm{BArF}]^{-}$} \\
Py & 936 & 14.2 & 10.8 \\
4-methylPy & 956 & 13.3 & 10.4 \\
2,4,6-trimethyl-3-nitroPy & 934 & 13.54 & 10.79 \\
3-bromo-2,4,6-trimethylPy & 968 & 14.19 & 10.49 \\
2,6-dimethylPy & 972 & 13.00 & 10.61 \\
2,4,6-trimethylPy & 988 & 13.01 & 10.24
\end{tabular}

aThe abbreviation Py stands for pyridine. bestimated at the B3LYP/6-311++G(3df,2p) level. 'Ref. 26, [BF4]- and [BArF]' as anions.

In Figure 4 are plotted the ${ }^{1} \mathrm{H}$ NMR chemical shifts of the conjugate acids of ortho-unsubstituted and orthomethylsubstituted pyridine derivatives and a-i with $[\mathrm{BArF}]^{-}$and $\left[\mathrm{BF}_{4}\right]^{-}$vs their PA. The complexes with $\left[\mathrm{BF}_{4}\right]^{-}$ exhibit a broad scattering of the $\delta\left({ }^{1} \mathrm{H}\right)$ values. In contrast, 
for the complexes with [BArF] $^{-}$the correlation is better and can be expressed as: $\delta^{0}\left({ }^{1} \mathrm{H}\right)=19.45 \mathrm{ppm}-0.00924 \frac{\mathrm{ppm} \cdot \mathrm{mol}}{\mathrm{kJ}} \cdot \mathrm{PA} \quad($ eq 2). We have used for this correlation only the values of ortho-methylsubstituted pyridines because of the smaller temperature dependence of these values. In Table 3 are compared the N...N distances in the proton-bound homodimers of the selected pyridine derivatives that were calculated using (i) the experimental values of $\delta\left({ }^{1} \mathrm{H}\right)$ in the conjugate acids with $[\mathrm{BArF}]^{-}$and (ii) the parameter $\delta^{0}\left({ }^{1} H\right)$ estimated from PA. The difference between these values represents the margin of error of the further estimations.

Figure 4. ${ }^{1} \mathrm{H}$ NMR chemical shifts $\left(\delta\left({ }^{1} \mathrm{H}\right)\right)$ of the mobile protons of conjugate acids vs the gas-phase proton affinities (PA) of the corresponding bases. Anion $\left[\mathrm{BF}_{4}\right]^{-}$: orthounsubstituted pyridines ( $\mathbf{\square})$; ortho-methylsubstituted pyridines $(\bullet)$; a-i $(\mathbf{\Lambda})$. Anion $[\mathrm{BArF}]^{-}$: ortho-unsubstituted pyridines (口); ortho-methylsubstituted pyridines (०). NMR data for the pyridines are taken from Ref. 26. The dotted line represents the dependence of $\delta\left({ }^{1} \mathrm{H}\right)$ on the PA for the conjugate acids of ortho-methylsubstituted pyridines with [BArF $]^{-}$.

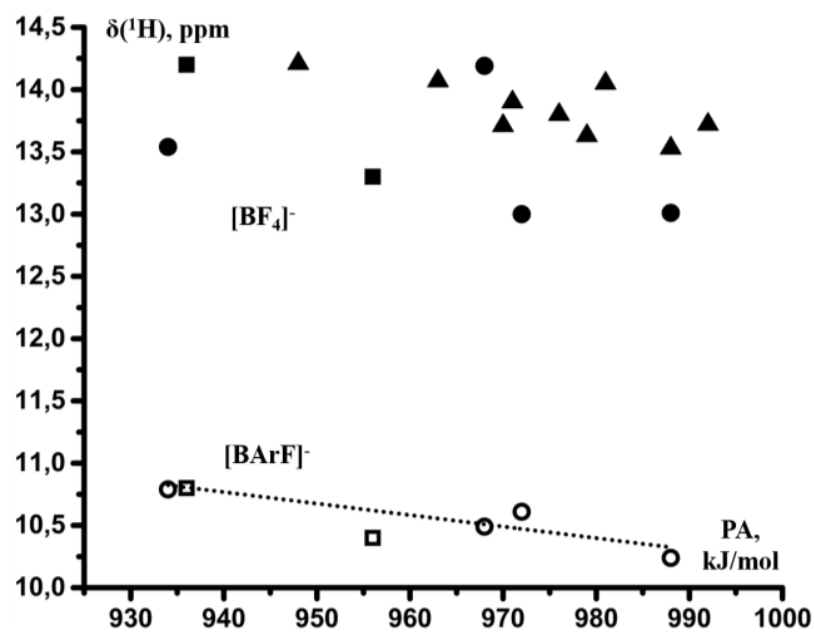

Table 3. Geometry of H-bonds in the proton-bound homodimers of some pyridine derivatives.

\begin{tabular}{lcc} 
Base $^{\mathrm{a}}$ & \multicolumn{2}{c}{$r_{N N}, \AA$} \\
\cline { 2 - 3 } Py & $\mathrm{i}^{\mathrm{b}}$ & ii $^{\mathrm{c}}$ \\
4-methylPy & 2.618 & 2.618 \\
2,4,6-trimethyl-3-nitroPy & 2.624 & 2.632 \\
3-bromo-2,4,6-trimethylPy & 2.695 & 2.697 \\
2,6-dimethylPy & 2.681 & 2.682 \\
2,4,6-trimethylPy & 2.670 & 2,664 \\
& 2.665 & 2.668
\end{tabular}

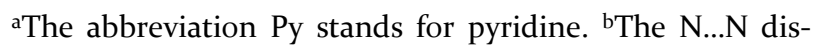
tances estimated using the experimental values of $\delta\left({ }^{1} \mathrm{H}\right){ }^{26}$ cThe same distances estimated using the parameter $\delta^{0}\left({ }^{1} H\right)$.
Thus, the parameter $\delta^{0}\left({ }^{1} H\right)$ for the conjugate acids of a-i can be estimated from their PA values using eq 2, Table 4. The H-bond distances in the proton-bound homodimers of a-i in solution in $\mathrm{CDF}_{3} / \mathrm{CDClF}_{2}$ are collected in Table 4. In order to simplify the further discussion, we have plotted the estimated N...N distances together with the available N...N distances in the proton-bound homodimers of pyridine derivatives as a function of the PA in Figure 5. The PA values of $N, N-2,6$-dimethylpyridin-4amine and N,N-2,6-tetramethylpyri-din-4-amine are 1013 $\mathrm{kJ} / \mathrm{mol}$ and $1035 \mathrm{~kJ} / \mathrm{mol}$, respectively.

Table 4. The $\mathrm{p} K_{\mathrm{a}} \mathrm{s}$, PA's, and the correlation parameter $\delta^{0}\left({ }^{1} H\right)$ of a-i and the geometry of $\mathrm{H}$-bonds in their protonbound homodimers in solution.

$\begin{array}{cccccc} & & \mathrm{PA}^{\mathrm{b}} & \delta^{0}\left({ }^{1} H\right) & r_{N H} & r_{N N} \\ \text { Base } & \mathrm{pK}_{\mathrm{a}}{ }^{\mathrm{a}} & \mathrm{kJ} / \mathrm{mol} & \mathrm{ppm} & \AA & \AA \\ \mathrm{a} & 4.2 & 948 & 10.69 & 1.199 & 2.599 \\ \mathrm{~b} & 5.0 & 963 & 10.55 & 1.200 & 2.598 \\ \mathrm{c} & 5.2 & 971 & 10.48 & 1.182 & 2.606 \\ \mathrm{~d} & 5.4 & 976 & 10.43 & 1.175 & 2.610 \\ \mathrm{e} & 4.4 & 970 & 10.49 & 1.140 & 2.638 \\ \mathrm{f} & 5.9 & 979 & 10.40 & 1.156 & 2.623 \\ \mathrm{~g} & 6.1 & 988 & 10.32 & 1.155 & 2.624 \\ \mathrm{~h} & 4.0 & 981 & 10.39 & 1.163 & 2.618 \\ \mathrm{i} & 5.6 & 992 & 10.28 & 1.166 & 2.616\end{array}$

aRef. [64] bstimated at the B3LYP/6-311++G(3df,2p) level.

Solvation effect on $\mathrm{H}$-bond geometries. Before starting the discussion of Figure 5, we remind the reader of the following points. The binding energies of proton-bound homodimers correlate with the PA in an approximately quadratic manner. ${ }^{27} \mathrm{We}$ are dealing with structurally similar homodimers for which the binding energy should correlate with the N...N distance. For the species under study, a decrease of the PA of a base causes an increase of the binding energy of its homodimer that should result in contraction of the N...N distance. ${ }^{26}$ In aprotic polar solvents, the difference in the PA values is attenuated. ${ }^{65}$ The degree of this attenuation should depend on the solvation features. A question arises whether Figure 5 provides hints about the solvation of the homodimers under study.

Quantitative analysis of effective acidities in aprotic solvents were beyond the scope of our study. Our objective was to get an estimate of the effective acidities of the conjugate acids of pyridines, quinolines, and acridines in a polar solution. As a measure of this effective acidity we use an effective proton affinity $\left(\mathrm{PA}^{\varepsilon}\right)$ that was calculated using the Polarizable Continuum Model (PCM). In Table 5 are collected $\mathrm{PA}^{\varepsilon}$ values calculated at $\varepsilon=109$. This value was larger than that of the $\mathrm{CDF}_{3} / \mathrm{CDClF}_{2}$ mixture. However, the PCM approximation is not sufficient for quantitative conclusions ${ }^{66}$ and the largest realistic value of $\varepsilon$ was selected in order to enhance the effect.

The geometries of the homodimers of 2,6methylsubstituted pyridines are affected by steric hindrance from the ortho-substituents and cannot be direct- 
ly compared to other homodimer in this study. The effect of steric hindrance, if any, on the geometry of the homodimers of 2-methylsubstituted quinolines $\mathbf{f}$ and $\mathbf{g}$ is less pronounced.

Figure 5. Experimental N...N distances $\left(\mathrm{r}_{\mathrm{NN}}\right)$ in the protonbound homodimers as a function of the calculated gas-phase proton affinities (PA): ortho-methylsubstituted pyridines $(\boldsymbol{\Delta})$, ortho-unsubstituted pyridines ( $\mathbf{a})$, orthomethylsubstituted quinolines $(\Delta)$, ortho-unsubstituted quinolines ( $\square$ ), and acridines ( $\circ)$. The selected pyridine derivatives: 2,4,6-trimethyl-3-nitropyridine (Coll-1), 3-bromo-2,4,6trimethylpyridine (Coll-2), 2,6-dimethylpyridine (Coll-3), 2,4,6-trimethylpyridine (Coll-4), N,N-2,6-tetramethylpyridin4-amine (Coll-5), pyridine (Py-1), 4-methylpyridine (Py-2), $N, N-2,6$-dimethylpyridin-4-amine $(\mathrm{Py}-3) . \mathrm{r}_{\mathrm{NN}}$ for the homodimers of pyridine derivatives were taken from Ref. 26. The PA of these species were calculated at the B3LYP/6$311++g(3 d f, 2 p)$ level. The dotted lines are for eye guidance only.

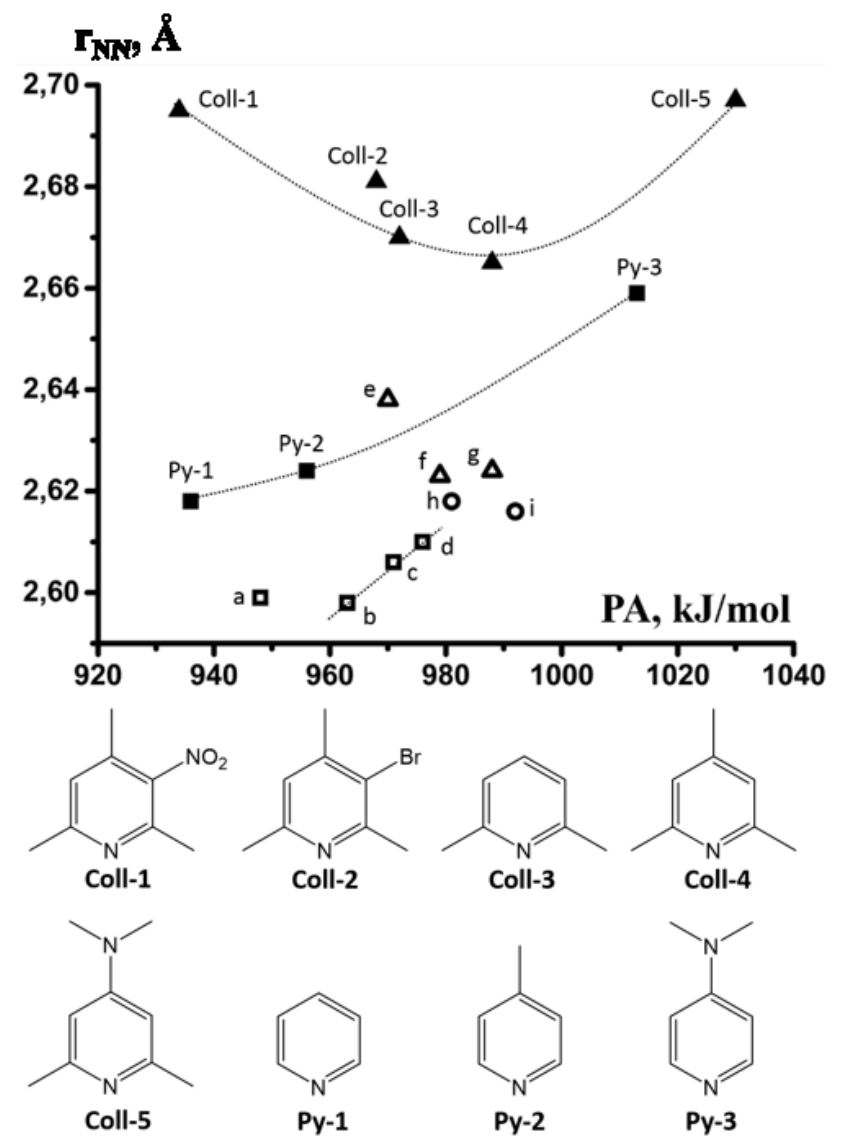

A decrease of the effective proton affinity in solution as compared to the gas phase is a trivial fact. A critical finding is that the attenuation increases in the sequence pyridine < quinoline $<$ acridine. The effect depends on the size of the species much stronger than on their electronic properties and/or their PA, Table 5. The use of another DFT functional $\left(\mathrm{B}_{97} \mathrm{D}_{3}\right)$ and/or solvation model (SMD) changes the numerical values but not the trend of the attenuation (see the Supporting Information). Thus, if a pyridine derivative Py and an acridine derivative Ac exhibit the same PA in the gas phase, in a polar solvent the effective proton affinity of Ac is smaller than that of Py. As a result, the N...N distance in the protonbound homodimer of Ac will be shorter compared with that of Py. Figure 5 perfectly demonstrates this effect for pyridines, quinolines, and acridine if to exclude $\mathbf{h}$ from the examination. Tentatively, the dependence of the solvation effect on the size of solute can be attributed to a local ordering of the solvent molecules. The larger the solute, the more ordering it makes on the solvation shell and thereby increases the local reaction field.

Table 5. The proton affinities $(\mathrm{kJ} / \mathrm{mol})$ of selected bases in the gas phase and at $\varepsilon=109$.

$\begin{array}{lcccc}\text { Base } & \mathrm{p} K_{\mathrm{a}}^{\mathrm{a}} & \mathrm{PA}^{\mathrm{b}} & \mathrm{PA}^{\varepsilon \mathrm{c}} & \Delta^{\mathrm{d}} \\ \text { Pyridine } & 5.2 & 936 & 711 & 225 \\ \text { 4-chloro-pyridine } & 3.2 & 924 & 701 & 223 \\ \text { Quinoline } & 5.0 & 963 & 713 & 250 \\ \begin{array}{l}\text { 4-chloro-quinoline } \\ \text { 5,6,7,8- }\end{array} & 3.6 & 952 & 704 & 248 \\ \text { tetrahydroquinoline } & 6.3 & 976 & 725 & 251 \\ \begin{array}{l}\text { acridine } \\ \text { 9-chloro-acridine }\end{array} & 5.6 & 992 & 722 & 270 \\ \begin{array}{l}\text { 1,2,3,4,5,6,7,8- } \\ \text { octahydroacridine }\end{array} & 7.0 & 981 & 712 & 269 \\ & & & & \\ \end{array}$

aRef. 64 b,cEstimated at the B3LYP/6-311++G(3df,2p) level 'Estimated using the Polarizable Continuum Model. ${ }^{\mathrm{d}} \Delta=\mathrm{PA}-$ $\mathrm{PA}^{\varepsilon}$.

The correlations shown in Figure 5 and their interpretation given above are not well fulfilled by the homodimers of $\mathbf{a}, \mathbf{h}, \mathbf{e}$, and somewhat Coll-2. All these species contain halogens as substituents. The data presented in Table 5 suggest that the solvent polarity does not affect specifically the inductive effect. We can speculate that the presence of halogen substituents affects the local ordering of $\mathrm{CDF}_{3}$ and $\mathrm{CDClF}_{2}$ molecules around the homodimers. This effect can be attributed either to a high localization of the charge at such substituents that competes with the [N$\mathrm{H}]^{+}$moiety for the orientation of the solvent molecules, or to a specific solvation of the halogen substituents by chemically similar $\mathrm{CDF}_{3}$ and $\mathrm{CDClF}_{2}$ molecules. Tentatively, we find the latter reason more credible. However, despite recent progress in halogen-bonding we are not aware how strong it can affect the proton-accepting power of heterocycles. ${ }^{6}$ Presumably, this effect can be analysed theoretically. 68

The data for homodimers of $\mathbf{a}, \mathbf{h}$, and $\mathbf{e}$ will fit the observed correlation better if their gas-phase PA will be increased by $15 \mathrm{~kJ} / \mathrm{mol}$. Thus, the attenuation of the proton affinity for these homodimers is smaller than for similar species. That means the solvation of $\mathbf{a}, \mathbf{h}$, and $\mathbf{e}$ results in a smaller effective solvent reactive field experiences by their $[\mathrm{N}-\mathrm{H} . . . \mathrm{N}]^{+}$moieties.

$\mathrm{H}$-bond geometry as a function of the dielectric permittivity. In Table 6 are collected experimental N...N distances of the proton-bound homodimers of pyridine (Py-1), quinoline (b), and acridine (i) in the $\mathrm{CDF}_{3} / \mathrm{CDClF}_{2}$ $(\varepsilon \approx 30)$ mixture and in the crystalline state and DFT calculated distances at the gas phase, the PCM $(\varepsilon=109)$, and PCM-SMD $(\varepsilon=109)$ approximations. The calculated N...N distances were dependent on the basis-set used (see the 
Supporting Information). Thus, the level of our calculations was not sufficient for quantitative conclusions. Here we analyze exclusively the general trend that needs to be studied in detail in the future.

All three homodimers exhibit a contraction of the N...N distances in the sequence gas phase (DFT) $>$ solid state (XRD) > polar solvent (NMR). In contrast, both implicit solvent models predict the opposite behavior for a polar solution that agrees with the results of more sophisticated studies reported in the past. ${ }^{29,69}$ Our results support the conclusion of Ref. 13 that implicit solvent models employed in computational studies do not reproduce experimental results for proton-bound homodimers. The reason for this result constitutes an open question. Presumably, molecular dynamics simulation with explicit treatment of solvent mixture should be able to reproduce the effect. Here we only mention that the PCM approximation predicts a contraction of the N...N distances compared with the gas phase in complexes of pyridine with phenol and N-phenylaniline, as well as in the protonbound homodimer of azane; in contrast, for the protonbound complex of [pyridine-H] ${ }^{+}$with $\mathrm{N}, \mathrm{N}-$ diphenylaniline, the homodimers of N,Ndimethylmethanamine and cyano(methyl)cyanamide the behavior is reversed (see the Supporting Information). Thus, both the PCM and PCM-SMD approximations fail to predict the effect of solvation on the geometrical and energetic parameters of bulky charged proton-bound molecular complexes.

Table 6. N...N distances ( $\AA$ ) in the proton-bound homodimers of pyridine, quinoline, and acridine.

$\begin{array}{lllc}\text { Method } & \text { Py-1 } & \mathbf{b} & \mathbf{i} \\ \mathrm{NMR} \text { in } \mathrm{CDF}_{3} / \mathrm{CDClF}_{2} & 2.618^{\mathrm{a}} & 2.598 & 2.616 \\ \mathrm{XRD} & 2.655^{\mathrm{a}} & - & 2.743^{\mathrm{b}} \\ & & & 2.754^{\mathrm{c}} \\ \text { DFT }^{\mathrm{d}} & 2.687 & 2.733 & 2.812 \\ \text { DFTe }^{\mathrm{N}} & 2.692 & 2.738 & 2.820 \\ \text { DFT PCM, } \varepsilon=108.94^{\mathrm{f}} & 2.748 & 2.793 & 2.885 \\ \text { DFT PCM-SMD, } \varepsilon=108.94^{\mathrm{f}} & 2.767 & 2.813 & -\end{array}$

aTaken from Ref. 26 bCocrystal with toluene. ${ }^{\text {cCocrystal }}$ with chloroform. dEstimated at the $\mathrm{B}_{3} \mathrm{LYP} / 6-311++\mathrm{G}(\mathrm{d}, \mathrm{p})$ level. eEstimated at the B3LYP/6-311++G(3df,2p) level. ${ }^{\mathrm{E} E s t i-}$ mated using the Polarizable Continuum Model at the B3LYP/6-311++G(3df,2p) level and $\varepsilon=109$.

\section{CONCLUSION}

In this work, we have experimentally studied the effect of solvation on the geometry of the proton-bound homodimers of pyridines, quinolines, and acridines. The main conclusion of this study is that the N...N distances in these homodimers in solution are shorter than in the gas phase. There are no reasons to doubt that solvation effects reported here can be extended to other H-bonded system embedded in a polar medium, whether the latter is a solution or an active center of enzyme. The effect of the medium on $\mathrm{H}$-bond geometry cannot be attributed exclusively to the macroscopic dielectric permittivity of the medium. The reactive field also depends on the size of the H-bonded system and the presence in the system of moieties that are subject to specific interactions with solvent molecules. In this sense, solvent is more like a crystal than a gas.

We reach the following specific conclusions from this study.

(i) The geometries of the proton-bound homodimers correlate with the gas-phase proton affinities (PA) of the corresponding bases. In particular, the $\mathrm{N}$... N distance becomes shorter upon a decrease of the PA.

(ii) This correlation remains valid within a series of species of different electronic structure but similar size.

(iii) An increase of the size of the system results in contraction of the N...N distance.

(iv) The correlation can be violated when the system contains substituents that specifically affect solvation features in a given solvent. In the case of the $\mathrm{CDF}_{3} / \mathrm{CDClF}_{2}$ mixture, such substituents are halogens that causes lengthening of the N...N distance.

(v) Neither the contraction of the N...N distance due to solvation nor the specific effect of substituents can be reproduced using the Polarizable Continuum Model.

(vi) The N...N distance in the homodimers of pyridine, quinoline, and acridine derivatives depends on the reaction field of the medium and decreases in the sequence gas phase $>$ solid state $>$ polar solvent.

\section{ASSOCIATED CONTENT}

Supporting Information. X-ray diffraction structure for single crystal [Acridine-H...Acridine $]^{+}[\mathrm{BArF}]^{-}$chloroform and $[$ Acridine-H...Acridine $]+[\mathrm{BArF}]$ toluene. The proton affinities of selected bases at $\varepsilon=109$ at the $311++\mathrm{g}(3 \mathrm{df}, 2 \mathrm{p})$ level. The N...N distances in the proton-bound homodimers of pyridine, azane, N,N-dimethylmethanamine, and cyano(methyl)cyanamide and the H-bonded complexes of pyridine with phenol, N-phenylaniline, and [N,Ndiphenylaniline- $\mathrm{H}]^{+}$calculated in the gas phase and polar solvents at different approximations. This material is available free of charge via the Internet at http://pubs.acs.org.

\section{AUTHOR INFORMATION}

\section{Corresponding Author}

Ilya.Shenderovich@chemie.uni-r.de

\section{ACKNOWLEDGMENT}

This work was supported by the German-Russian Interdisciplinary Science Center (G-RISC) funded by the German Federal Foreign Office via the German Academic Exchange Service (DAAD) and the Russian Foundation for Basic Research (Project 17-03-00590). We gratefully acknowledge the Gauss Centre for Supercomputing e.V. (www.gauss-centre.eu) for funding this project by providing computing time on the GCS Supercomputer SuperMUC at Leibniz Supercomputing Centre (LRZ, www.lrz.de)

\section{REFERENCES}


(1) Hydrogen-Transfer Reactions; Hynes, J. T., Klinman, J. P., Limbach, H. H., Schowen, R. L., Eds.; WILEY-VCH: Weinheim, 2007.

(2) Baranov, M. S.; Lukyanov, K. A.; Borissova, A. O.; Shamir, J.; Kosenkov, D.; Slipchenko, L. V.; Tolbert, L. M.; Yampolsky, I. V.; Solntsev, K. M. Conformationally Locked Chromophores as Models of Excited-State Proton Transfer in Fluorescent Proteins. J. Am. Chem. Soc. 2012, 134, 6025-6032.

(3) Grzegorzek, J.; Filarowski, A.; Mielke, Z. The Photoinduced Isomerization and its Implication in the Photo-Dynamical Processes in Two Simple Schiff Bases Isolated in Solid Argon. Phys. Chem. Chem. Phys. 2011, 13, 16596-16605.

(4) Filarowski, A.; Koll, A.; Sobczyk, L. Intramolecular Hydrogen Bonding in o-Hydroxy Aryl Schiff Bases. Curr. Org. Chem. 20o9, 13, 172-193.

(5) Shenderovich, I. G.; Lesnichin, S. B.; Tu, C.; Silverman, D. N.; Tolstoy, P. M.; Denisov, G. S.; Limbach, H.-H. NMR Studies of Active-Site Properties of Human Carbonic Anhydrase II by Using ${ }^{15} \mathrm{~N}$-Labeled 4-Methylimidazole as a Local Probe and Histidine Hydrogen-Bond Correlations. Chem. Eur. J. 2015, 21, 2915-2929.

(6) Limbach, H.-H.; Chan-Huot, M.; Sharif, S.; Tolstoy, P. M.; Shenderovich, I. G.; Denisov, G. S. Critical Hydrogen Bonds and Protonation States of Pyridoxal 5'-phosphate Revealed by NMR. BBA - Proteins and Proteomics 2011, 1814, 1426-1437.

(7) Mauder, D.; Akcakayiran, D.; Lesnichin, S. B.; Findenegg, G. H.; Shenderovich, I. G. Acidity of Sulfonic and Phosphonic Acid-Functionalized SBA-15 under Almost Water-Free Conditions. J. Phys. Chem. C 2009, 113, 19185-19192.

(8) Lesnichin, S. B.; Shenderovich, I. G.; Muljati, T.; Limbach, H.H.; Silverman, D. N. Intrinsic Proton Donating Power of Zincbound Water in a Carbonic Anhydrase Active Site Model Estimated by NMR. J. Am. Chem. Soc. 2o11, 133, 11331-11338.

(9) Poberžnik, M.; Purg, M.; Repič, M.; Mavri, J.; Vianello, R. Empirical Valence Bond Simulations of the Hydride-Transfer Step in the Monoamine Oxidase A Catalyzed Metabolism of Noradrenaline. J. Phys. Chem. B 2016, 120, 11419-11427.

(10) Vianello, R.; Domene, C.; Mavri, J. The Use of Multiscale Molecular Simulations in Understanding a Relationship between the Structure and Function of Biological Systems of the Brain: The Application to Monoamine Oxidase Enzymes. Front Neurosci. 2016, $10,327$.

(11) Kržan, M.; Vianello, R.; Maršavelski, A.; Repič, M.; Zakšek, M.; Kotnik, K.; Fijan, E.; Mavri, J. The Quantum Nature of DrugReceptor Interactions: Deuteration Changes Binding Affinities for Histamine Receptor Ligands. PLoS ONE 2016, 11, e0154002.

(12) Kisovec, M.; Rezelj, S.; Knap, P.; Cajnko, M.M.; Caserman, S.; Flašker, A.; Žnidaršič, N.; Repič, M.; Mavri, J.; Ruan, Y.; Scheuring, S.; Podobnik, M.; Anderluh, G. Engineering a pH Responsive Pore Forming Protein. Sci. Rep. 2017, 7, 42231.

(13) Pollice, R.; Bot, M.; Kobylianskii, I. J.; Shenderovich, I. G.; Chen, P. Attenuation of London Dispersion in Dichloromethane Solutions. J. Am. Chem. Soc. 2017, 139, 13126-13140.

(14) Sigalov, M. V.; Kalish, N.; Carmeli, B.; Pines, D.; Pines, E. Probing Small Protonated Water Clusters in Acetonitrile Solutions by 1 H NMR. Z. Phys. Chem. 2013, 227, 983-1007.

(15) Vener, M. V.; Kong, S.; Levina, A. A.; Shenderovich, I. G. Spectroscopic Signatures of $\left[\mathrm{H}_{9} \mathrm{O}_{4}\right]^{+}$and $\left[\mathrm{H}_{13} \mathrm{O}_{6}\right]^{+}$Ions in a Polar Aprotic Environment Revealed under DFT-PCM Approximation. Acta Chim. Slov. 2011, 58, 402-410.

(16) Vener, M. V.; Shenderovich, I. G.; Rykounov, A. A. A Qualitative Study of the Effect of a Counterion and Polar Environment on the Structure and Spectroscopic Signatures of a Hydrated Hydroxyl Anion. Theor. Chem. Acc. 2013, 132, 1361.
(17) Sharif, S.; Shenderovich, I. G.; González, L.; Denisov, G. S.; Silverman, D. N.; Limbach, H.-H. NMR and Ab initio Studies of Small Complexes Formed between Water and Pyridine Derivatives in Solid and Liquid Phase. J. Phys. Chem. A 2007, 111, 6o846093.

(18) Begimova, G. U.; Tupikina, E. Yu.; Yu, V. K.; Denisov, G. S.; Bodensteiner, M.; Shenderovich, I. G. Effect of Hydrogen Bonding to Water on the ${ }^{31} \mathrm{P}$ Chemical Shift Tensor of Phenyl- and Trialkylphosphine Oxides and a-Amino Phosphonates. J. Phys. Chem. C 2016, 16, 8717-8729.

(19) Gurinov, A. A.; Mauder, D.; Akcakayiran, D.; Findenegg, G. H.; Shenderovich, I. G. Does Water Affect the Acidity of Surfaces? The Proton-Donating Ability of Silanol and Carboxylic Acid Groups at Mesoporous Silica. ChemPhysChem 2012, 13, 22822285 .

(20) Gruenberg, B.; Emmler, T.; Gedat, E.; Shenderovich, I.; Findenegg, G. H.; Limbach, H.-H.; Buntkowsky, G. Hydrogen Bonding of Water Confined in Mesoporous Silica MCM-41 and SBA-15 Studied by ${ }^{1} \mathrm{H}$ Solid-State NMR. Chem. Eur J. 2004, 10, 5689-5696.

(21) Borissova, A. O.; Lyssenko, K. A.; Gurinov, A. A.; Shenderovich, I. G. Energy Analysis of Competing Non-Covalent Interaction in $1: 1$ and $1: 2$ Adducts of Collidine with Benzoic Acids by Means of X-Ray Diffraction. Z. Phys. Chem. 2013, 227, 775-790.

(22) Limbach, H.-H.; Tolstoy, P. M.; Pérez-Hernández, N.; Guo, J.; Shenderovich, I. G.; Denisov, G. S. OHO Hydrogen Bond Geometries and NMR Chemical Shifts: From Equilibrium Structures to Geometric H/D Isotope Effects, with Applications for Water, Protonated Water, and Compressed Ice. Israel J. Chem. 2009, 49, 199-216.

(23) Iogansen, A. V. Direct Proportionality of the Hydrogen Bonding Energy and the Intensification of the Stretching $v(\mathrm{XH})$ Vibration in Infrared Spectra. Spectrochim. Acta. A 1999, 55, 1585-1612.

(24) Kumar, G. A.; McAllister, M. A. Theoretical Investigation of the Relationship between Proton NMR Chemical Shift and Hydrogen Bond Strength. J Org Chem. 1998, 63, 6968-6972.

(25) Novak, A. Hydrogen Bonding in Solids. Correlation of Spectroscopic and Crystallographic Data. Struct. Bonding 1974, 18, 177-216.

(26) Gurinov, A. A.; Lesnichin, S. B.; Limbach, H.-H.; Shenderovich, I. G. How Short is the Strongest Hydrogen Bond in the Proton-Bound Homodimers of Pyridine Derivatives? J. Phys. Chem. A 2014, 118, 10804-10812.

(27) Chan, B.; Del Bene, J. E.; Radom, L. Proton-Bound Homodimers: How Are the Binding Energies Related to Proton Affinities? J. Am. Chem. Soc. 2007, 129, 12197-12199.

(28) Masuda, Y.; Mori, Y.; Sakurai, K. Effects of Counterion and Solvent on Proton Location and Proton Transfer Dynamics of N$\mathrm{H}$... N Hydrogen Bond of Monoprotonated 1,8Bis(dimethylamino)naphthalene. J. Phys. Chem. A 2013, 117, 10576-10587.

(29) Mori, Y.; Takano, K. Location of Protons in N-H $\cdots \mathrm{N}$ Hydrogen-Bonded Systems: a Theoretical Study on Intramolecular Pyridine-Dihydropyridine and Pyridine-Pyridinium Pairs. Phys. Chem. Chem. Phys. 2012, 14, 11090-11098.

(30) Pietrzak, M.; Wehling, J. P.; Kong, S.; Tolstoy, P. M.; Shenderovich, I. G.; Lopez, C.; Claramunt, R. M.; Elguero, J.; Denisov, G. S. ; Limbach, H.-H. Symmetrization of Cationic Hydrogen Bridges of Protonated Sponges Induced by Solvent and Counteranion Interactions as Revealed by NMR Spectroscopy. Chem. Eur. J. 2010, 16, 1679-169o.

(31) Shenderovich, I. G.; Burtsev, A. P.; Denisov, G. S.; Golubev, N. S.; Limbach, H.-H. Influence of the Temperature-Dependent 
Dielectric Constant on the H/D Isotope Effects on the NMR Chemical Shifts and the Hydrogen Bond Geometry of Collidine$\mathrm{HF}$ Complex in $\mathrm{CDF}_{3} / \mathrm{CDClF}_{2}$ Solution. Magn. Reson. Chem. 2001, 39, S91-S99.

(32) Yakelis, N. A.; Bergman, R. G. Safe Preparation and Purification of Sodium Tetrakis[(3,5-trifluoromethyl)phenyl]borate (NaBArF24): Reliable and Sensitive Analysis of Water in Solutions of Fluorinated Tetraarylborates. Organometallics 2005, 24, 3579-3581.

(33) Lesnichin, S. B.; Tolstoy, P. M.; Limbach, H.-H.; Shenderovich, I. G. Counteranion-Dependent Mechanisms of Intramolecular Proton Transfer in Aprotic Solution. Phys. Chem. Chem. Phys. 2010, 12, 10373-10379.

(34) Dolomanov, O. V.; Bourhis, L. J.; Gildea, R. J.; Howard, J. A. K.; Puschmann, H. OLEX2: a Complete Structure Solution, Refinement and Analysis Program. J. Appl. Cryst. 2009, 42, 339-341. (35) Sheldrick, G. M. A Short History of SHELX. Acta Cryst. 2008, A64, 112-122.

(36) Frisch, M. J.; Trucks, G. W.; Schlegel, H. B.; Scuseria, G. E.; Robb, M. A.; Cheeseman, J. R.; Scalmani, G.; Barone, V.; Mennucci, B.; Petersson, G. A., et al. Gaussian 16, Revision A.03; Gaussian, Inc.: Wallingford, CT, 2016.

(37) Zhu, H.; Blom, M.; Compagnon, I.; Rijs, A. M.; Roy, S.; von Helden, G.; Schmidt, B. Conformations and Vibrational Spectra of a Model Tripeptide: Change of Secondary Structure upon Micro-Solvation. Phys. Chem. Chem. Phys. 2010, 12, 3415-3425. (38) Moser, A.; Range, K.; York, D. M. Accurate Proton Affinity and Gas-Phase Basicity Values for Molecules Important in Biocatalysis. J. Phys. Chem. B 2010, 114, 13911-13921.

(39) Tomasi, J.; Mennucci, B.; Cammi, R. Quantum Mechanical Continuum Solvation Models. Chem. Rev. 2005, 105, 2999-3094.

(40) Kong, S.; Borissova, A. O.; Lesnichin, S. B.; Hartl, M.; Daemen, L. L.; Eckert, J.; Antipin, M. Yu.; Shenderovich, I. G. Geometry and Spectral Properties of the Protonated Homodimer of Pyridine in the Liquid and Solid States. A Combined NMR, X-ray Diffraction and Inelastic Neutron Scattering Study. J. Phys. Chem. A 2011, 115, 8041-8048.

(41) Filarowski, A. Intramolecular Hydrogen Bonding in OHydroxyaryl Schiff Bases. J. Phys. Org. Chem. 2005, 18, 686-698. (42) Shenderovich, I. G.; Tolstoy, P. M.; Golubev, N. S.; Smirnov, S. N.; Denisov, G. S.; Limbach, H.-H. Low-Temperature NMR Studies of the Structure and Dynamics of a Novel Series of AcidBase Complexes of HF with Collidine Exhibiting Scalar Couplings Across Hydrogen Bonds. J. Am. Chem. Soc. 2003, 125, 1171011720.

(43) Golubev, N. S.; Melikova, S. M.; Shchepkin, D. N.; Shenderovich, I. G.; Tolstoy, P. M.; Denisov, G. S. Interpretation of H/D Isotope Effects on NMR Chemical Shifts of [FHF]- Ion Based on Calculations of Nuclear Magnetic Shielding Tensor Surface. $Z$. Phys. Chem. 2003, 217, 1549-1563.

(44) Schah-Mohammedi, P.; Shenderovich, I. G.; Detering, C. ; Limbach, H.-H.; Tolstoy, P. M.; Smirnov, S. N.; Denisov, G. S.; Golubev, N. S. H/D-Isotope Effects on NMR Chemical Shifts and Symmetry of Homoconjugated Hydrogen-Bonded Ions in Polar Solution. J. Am. Chem. Soc. 200o, 122, 12878-12879.

(45) Golubev, N. S.; Shenderovich, I. G.; Smirnov, S. N.; Denisov, G. S.; Limbach, H.-H. Nuclear Scalar Spin-Spin Coupling Reveals Novel Properties of Low-Barrier Hydrogen Bonds in a Polar Environment. Chem. Eur. J. 1999, 5, 492-497.

(46) Vener, M. V. Model Study of the Primary H/D Isotope Effects on the NMR Chemical Shift in Strong Hydrogen-Bonded Systems. Chem. Phys. 1992, 166, 311-316.

(47) Golubev, N. S.; Detering, C.; Smirnov, S. N.; Shenderovich, I. G.; Denisov, G. S.; Limbach, H.-H.; Tolstoy, P. M. H/D Isotope
Effects on NMR Chemical Shifts of Nuclei Involved in a Hydrogen Bridge of Hydrogen Isocyanide Complexes with Fluoride Anion. Phys. Chem. Chem. Phys. 2009, 11, 5154-5159.

(48) Chan, B.; Del Bene, J. E.; Radom, L. What Factors Determine Whether a Proton-Bound Homodimer Has a Symmetric or an Asymmetric Hydrogen Bond? Mol. Phys. 2009, 107, 1095-1105. (49) Reed, J. L. Electronegativity: Proton Affinity. J. Phys. Chem. 1994, 98, 10477-10483.

(50) Melikova, S. M.; Rutkowski, K. S.; Gurinov, A. A.; Denisov, G. S.; Rospenk, M.; Shenderovich, I. G. FTIR Study of the Hydrogen Bond Symmetry in Protonated Homodimers of Pyridine and Collidine in Solution. J. Mol. Struct. 2012, 1018, 39-44.

(51) Shenderovich I. G. Qualitative Analysis of the Geometry of the Hydrogen Bond in the Homoconjugated Pyridine Ion. Russ. J. Gen. Chem. 2007, 77, 620-625.

(52) Perrin, C. L. Symmetry of Hydrogen Bonds in Solution. Pure Appl. Chem. 2009 ,81, 571-583.

(53) Perrin, C. L.; Karri, P. Are There Single-Well Hydrogen Bonds in Pyridine-Dichloroacetic Acid Complexes? Chem. Commun. 2010, 46, 481-483.

(54) Perrin, C. L.; Burke, K. D. Variable-Temperature Study of Hydrogen-Bond Symmetry in Cyclohexene-1,2-dicarboxylate Monoanion in Chloroform-d. J. Am. Chem. Soc. 2014, 136, 43554362.

(55) Warschel, A.; Bora, R. P. Perspective: Defining and Quantifying the Role of Dynamics in Enzyme Catalysis. J. Chem. Phys. 2016, 144, 18091.

(56) Lorente, P.; Shenderovich, I. G.; Golubev, N. S.; Denisov, G. S.; Buntkowsky, G.; Limbach, H.-H. ${ }^{1} \mathrm{H} /{ }^{15} \mathrm{~N}$ NMR Chemical Shielding, Dipolar ${ }^{15} \mathrm{~N},{ }^{2} \mathrm{H}$ Coupling and Hydrogen Bond Geometry Correlations in a Novel Serious of Hydrogen-Bonded AcidBase Complexes of Collidine with Carboxylic Acids. Magn. Reson. Chem. 2001, 39, S18-S29.

(57) Pietrzak, M.; Shibl, M. F.; Broring, M.; Kuhn, O.; Limbach, H.-H. ${ }^{1} \mathrm{H} /{ }^{2} \mathrm{H}$ NMR Studies of Geometric H/D Isotope Effects on the Coupled Hydrogen Bonds in Porphycene Derivatives. J. Am. Chem. Soc. 2007, 129, 296-304.

(58) Limbach, H.-H.; Pietrzak, M.; Sharif, S.; Tolstoy, P. M.; Shenderovich, I. G.; Smirnov, S. N.; Golubev, N. S.; Denisov, G. S. NMR-Parameters and Geometries of OHN- and ODN Hydrogen Bonds of Pyridine-Acid Complexes. Chem. Eur J. 2004, 10, 51955204.

(59) Ip, B. C. K.; Shenderovich, I. G.; Tolstoy, P. M.; Frydel, J.; Denisov, G. S.; Buntkowsky, G.; Limbach H.-H. NMR Studies of Solid Pentachlorophenol-4-Methylpyridine Complexes Exhibiting Strong OHN Hydrogen Bonds: Geometric H/D Isotope Effects and Hydrogen Bond Coupling Cause Isotopic Polymorphism. J. Phys. Chem. A 2012, 116, 11370-11387.

(6o) Tolstoy, P. M.; Smirnov, S. N.; Shenderovich, I. G.; Golubev, N. S.; Denisov, G. S.; Limbach, H.-H. NMR Studies of Solid State - Solvent and H/D Isotope Effects on Hydrogen Bond Geometries of 1:1 Complexes of Collidine with Carboxylic Acids. J. Molec. Struct. 2004, 700, 19-27.

(61) Andreeva, D. V.; Ip, B.; Gurinov, A. A.; Tolstoy, P. M.; Shenderovich, I. G.; Limbach, H.-H. Geometrical Features of Hydrogen Bonded Complexes Involving Sterically Hindered Pyridines. J. Phys. Chem. A 2006, 110, 10872-10879.

(62) Morgan, S. O.; Lowry, H. H. Dielectric Polarization of Some Pure Organic Compounds in the Dissolved, Liquid, and Solid States. J. Phys. Chem. 1930, 34, 2385-2432.

(63) Sham, Y. Y.; Chu, Z. T.; Warshel, A. Consistent Calculations of $\mathrm{p} K_{\mathrm{a}}$ 's of Ionizable Residues in Proteins: Semi-microscopic and Microscopic Approaches. J. Phys. Chem. B 1997, 101, 4458-4472. (64) SciFinder ${ }^{\circledast}$. https://scifinder.cas.org/. 
(65) Taft, R. W.; Bordwell, F. G. Structural and Solvent Effects Evaluated from Acidities Measured in Dimethyl Sulfoxide and in the Gas Phase. Acc. Chem. Res. 1988, 21, 463-469.

(66) Kong, S.; Shenderovich, I. G.; Vener, M. V. Density Functional Study of the Proton Transfer Effect on Vibrations of Strong (Short) Intermolecular $\mathrm{O}-\mathrm{H} \cdots \mathrm{N} / \mathrm{O}^{-} \cdots \mathrm{H}^{-\mathrm{N}^{+}}$Hydrogen Bonds in Aprotic Solvents. J. Phys. Chem. A 2010, 114, 2393-2399.

(67) Kolář, M. H.; Hobza, P. Computer Modeling of Halogen Bonds and Other $\sigma$-Hole Interactions. Chem. Rev. 2016, 116, $5155-5187$.

(68) Kakeshpour, T.; Wu, J. I.; Jackson, J. E. AMHB: (Anti)aromaticity-Modulated Hydrogen Bonding. J. Am. Chem. Soc. 2016, 138, 3427-3432.

(69) Tayyari, S. F.; Mahdizadeh, S.; Halakoei, J; Wang, Y. A. Vibrational Assignment and Proton Tunneling in PyridinePyridinium Complexes. J. Mol. Struct. 2010, 971, 39-46. 


1
2
3
4
5
6
7
8
9
10
11
12
13
14
15
16
17
18
19
20
21
22
23
24
25
26
27
28
29
30
31
32
33
34
35
36
37
38
39
40
41
42
43
44
45
46
47
48
49
50
51
52
53
54
56
59

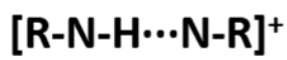

$\mathrm{R}=$ pyridine, quinoline, acridine

N...N distance

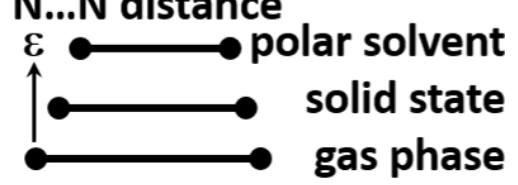

TOC Graphic

1 